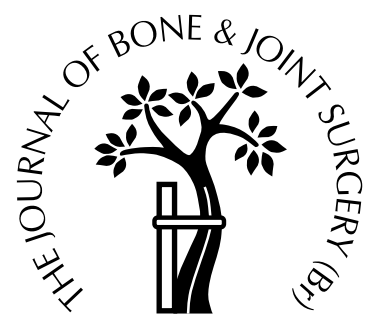

\title{
Coral grafting supplemented with bone marrow
}

\author{
S. Louisia, M. Stromboni, A. Meunier, L. Sedel, H. Petite \\ From the Universite D. Diderot, Paris, France
}

$\mathbf{L}$ imited success in regenerating large bone defects has been achieved by bridging them with osteoconductive materials. These substitutes lack the osteogenic and osteoinductive properties of bone autograft. A direct approach would be to stimulate osteogenesis in these biomaterials by the addition of fresh bone-marrow cells (BMC).

We therefore created osteoperiosteal gaps $2 \mathrm{~cm}$ wide in the ulna of adult rabbits and either bridged them with coral alone (CC), coral supplemented with BMC, or left them empty. Coral was chosen as a scaffold because of its good biocompatibility and resorbability. In osteoperiosteal gaps bridged with coral only, the coral was invaded chiefly by fibrous tissue. It was insufficient to produce union after two months. In defects filled with coral and BMC an increase in osteogenesis was observed and the bone surface area was significantly higher compared with defects filled with coral alone. Bony union occurred in six out of six defects filled with coral and BMC after two months. An increase in the resorption of coral was also observed, suggesting that resorbing cells or their progenitors were present in bone marrow and survived the grafting procedure. Our findings have shown that supplementation of coral with BMC increased both the resorption of material and osteogenesis in defects of a clinical significance.

J Bone Joint Surg [Br] 1999;81-B:719-24.

Received 5 August 1998; Accepted after revision 4 December 1998

S. Louisia, MD, Orthopaedic Surgeon

M. Stromboni, MD, Orthopaedic Surgeon

A. Meunier, Scientist

L. Sedel, MD, Professor of Orthopaedic Surgery

H. Petite, PhD, Scientist

Laboratoire de Recherches Orthopédiques, Université D. Diderot, UPRES A CNRS 7052, 10 Avenue de Verdun, 75010 Paris, France.

Correspondence should be sent to Dr H. Petite.

(C)1999 British Editorial Society of Bone and Joint Surgery 0301-620X/99/49358 \$2.00
The preferred treatment of a segmental bone defect is by autologous bone graft because of its osteoinductivity. Such material is, however, in limited supply and its harvest implies additional morbidity. The difficulty of fabricating a functional shape from the graft may result in less than optimal filling of the defect. To overcome these problems, bone allografts and bone substitutes have been developed, but they have their own limitations. ${ }^{1}$

Recent advances in the field of tissue engineering have allowed new substitutes to be considered which combine the properties of biomaterials with biologically active tissue-inducing substances or cells. ${ }^{2}$ The rationale for using bone marrow is that it contains stem cells which have the potential to differentiate along a variety of pathways including that to bone cells. ${ }^{3,4}$ Depending on the extent of the defect, supplementation of the biomaterial with bone marrow can be carried out with either fresh whole marrow or in vitro expanded populations of bone-marrow cells. ${ }^{5}$ Fresh whole marrow has been used to enhance osteogenesis of calcium phosphate ceramic in ectopic ${ }^{6,7}$ or orthotopic models. ${ }^{8-10}$ No assessment has been made of a combination of calcium carbonate and bone-marrow cells (BMC) in bone defects. Our study was designed to determine whether fresh BMC in combination with coral could regenerate a large segmental bone defect which would otherwise not repair. We chose coral as a scaffold because of its interconnected porous architecture, high compressive breaking stress, good biocompatibility and resorbability.

The experiment was devised to compare the healing potential of fresh BMC delivered on a porous coral biomatrix with that of the biomatrix alone, or a defect left empty.

\section{Materials and Methods}

We used 39 New Zealand White rabbits provided by CEGAV (Saint-Mars-d'Egrenne, France). All the rabbits were four months old and were checked for closure of the growth plates. They weighed 3.0 to $3.5 \mathrm{~kg}$. They were kept singly in metal hutches at a temperature of $21^{\circ} \mathrm{C}$ and with $50 \%$ air humidity according to the European guidelines for care and use of laboratory animals. Artificial lighting was used to maintain a normal day/night rhythm.

Coral implants. Coral exoskeleton from Porites sp. (Bicoral, Inoteb, France) was used in the form of cylindri- 
cal blocks $6 \mathrm{~mm}$ in diameter and $20 \mathrm{~mm}$ long. It consists of calcium carbonate $(98 \%$ to $99 \%)$ in the form of aragonite with trace elements $(0.5 \%$ to $1 \%)$ and amino acids $(0.07 \pm$ $0.02 \%)$. The volume porosity and the mean pore diameter were $49 \pm 2 \%$ and $250 \mu \mathrm{m}$ (150 to 400 ), respectively. All pores intercommunicated. The coral implants were sterilised by autoclaving which did not affect the composition. ${ }^{11}$ The implants were shaped into the form of a cone which allowed them to be wedged between the bone ends.

Bone marrow hybrid implant. Autologous BMC were obtained by drilling a hole in the rabbit's tibia and aspirating the cells using a heparinised syringe. Bone-marrow smears were prepared and examined by a haematologist. A single-cell suspension was prepared by repeatedly aspirating the cells successively through 18-gauge and 21-gauge needles. The coral implants were loaded with $10^{8}$ nucleated cells placed in $1 \mathrm{ml}$ of $\alpha$-minimum essential medium (MEM) containing 100 units/ml of penicillin, streptomycin and hydroxyethylpiperazine ethane sulphate buffer. The implant was placed in this solution for two hours. The hybrid implant was incubated with $\alpha$-MEM (4 ml) overnight at $37^{\circ} \mathrm{C}$ in a humidified atmosphere of $95 \%$ air and $5 \% \mathrm{CO}_{2}$. SEM and histological examinations were carried out to check for cell adhesion and cell penetration within the implant.

Operative technique. The rabbits were anaesthetised using intramuscular injections of ketamine hydrochloride $(100 \mathrm{mg} / \mathrm{kg})$, medetomidine hydrochloride $(0.25 \mathrm{mg} / \mathrm{kg})$ and diazepam $(0.5 \mathrm{mg} / \mathrm{kg})$. Prophylactic antibacterial treatment consisted of cefalexine at a dose of $25 \mathrm{mg} / \mathrm{kg}$.

The surgical procedure was carried out as described by Tuli and Singh ${ }^{12}$ with slight modification. After the induction of anaesthesia, the rabbit was aseptically prepared and draped for operation on the right upper limb. Using a direct approach, the ulna was exposed and a mid-diaphyseal segment of bone with its periosteum, $2 \mathrm{~cm}$ in size, was removed using a circular saw under irrigation with saline solution. The size of each defect was checked using a ruler. The osteoperiosteal gap was thoroughly rinsed with physiological saline and any bone fragments were washed out. The defects were either left empty as controls or completely filled with one of the biomaterials. No osteosynthesis was used since the radio-ulnar synostosis provides enough stability in the rabbit. The muscles, fascia and skin were closed. After disinfection the site of operation was then covered with an adhesive bandage. Postoperative radiographs of the ulna were taken to check for the placement of the implant material. After one, two or four months, the rabbits were killed using an overdose of pentobarbital.

Experimental groups. The 39 rabbits were randomly assigned to one of the following groups: 1) a control group in which the defects were left empty (six rabbits were allowed to heal for four weeks, six for eight weeks and three for four months); 2) group $\mathrm{CC}$ in which the defect was filled with a coral implant; and 3) group CC-BMC, the
Table I. Experimental design and distribution of animals within groups

\begin{tabular}{llll}
\hline & 1 month & 2 months & 4 months \\
\hline Control & 6 & 6 & 3 \\
CC & 6 & 6 & - \\
CC-BMC & 6 & 6 & - \\
\hline
\end{tabular}

hybrid implant group, which had coral and BMC. Six rabbits were allowed to heal for four weeks and six other rabbits for eight weeks in the two latter groups (Table I).

Radiographs. When the animals were killed radiographs were taken of the ulna.

Histology. At one, two or four months, the ulna and soft tissues were harvested. Specimens were fixed in formalin (10\%), dehydrated into ethanol, cleared in xylene and embedded in methylmethacrylate. The bones were cut lengthways using a circular water-cooled diamond saw (200 to $300 \mu \mathrm{m})$. The cuts were carried out in the coronal plane of the forelimb including the radius and the ulna. We selected the cut which was the closest to the coronal plane and which included the entire length of the implant and the two cut ends of the ulna. The histological histomorphometric evaluations were carried out on this central cut. The sections then were ground down to a thickness of $100 \mu \mathrm{m}$, polished, and surface-stained with Stevenel Blue and Van Gieson picro-fuchsin for light microscopy and histomorphometric analysis. ${ }^{13}$

Histomorphometry. Histomorphometry was carried out using a microscope linked to an image-processing system (Quantimet Q500, Cambridge, UK) using a 3-CCD videocamera (DXC-930P; Sony, Paris, France). Once the image had been digitised, we obtained a given rectangular surface $(1 \times 2 \mathrm{~cm})$ which included the whole implant and the two cut ends of the defect. The staining allowed the colour video camera to differentiate coral from bone. The total surface area, coral surface area and bone surface area (BSA) were determined in this rectangular using customised software.

Statistical analysis. Statistical significance was determined by one-way analysis of variance (ANOVA) and unpaired Student's $t$-tests $(\mathrm{p}<0.05)$.

\section{Results}

Procedural morbidity and mortality. All rabbits were able to walk within three hours of surgery. Two specimens were excluded from the analysis because of a further fracture of the ulna in one control rabbit at four weeks and for displacement of the implant in one rabbit in group CC at four weeks.

Radiographs. The results are shown in Figure 1. At four and eight weeks, no union was observed in the control group (Fig. 1A). Scanty formation of new bone was seen to originate from the edge of the defect. At 16 weeks, however, one-third of the osteoperiosteal gap had repaired. 

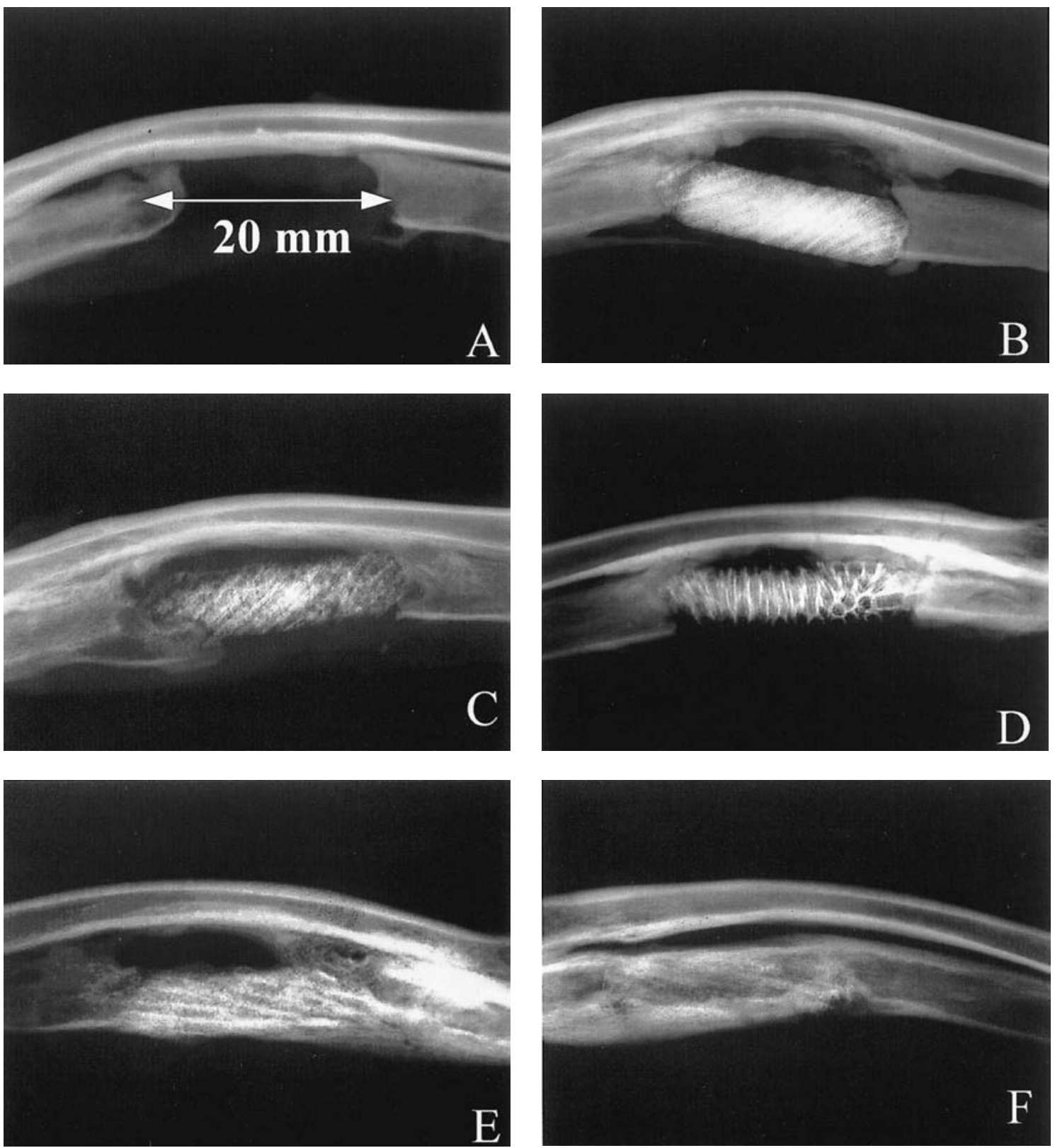

Fig. 1

Lateral postmortem specimen radiographs of A) defects left empty, B and C) filled with coral and D, E and F) coral supplemented with BMC. There is a high degree of resorption of coral in defects filled with CC-BMC in comparison with defects filled with CC at four weeks $(\mathrm{D} v \mathrm{~B})$ and eight weeks $(\mathrm{E}$ and $\mathrm{F} v \mathrm{C})$. Osteogenesis was increased in defects filled with CC-BMC in comparison with defects filled with CC.

In the $\mathrm{CC}$ group, no bridging of the osteoperiosteal gap was observed radiologically at four weeks (Fig. 1B). The coral was clearly visible. Between four and eight weeks, a decrease in the density of the coral was seen representing resorption (Fig. 1C), but the amount of formation of new bone did not increase.

In the $\mathrm{CC}-\mathrm{BMC}$ group, at four weeks addition of BMC dramatically increased resorption of the implant and formation of bone. Initially, no bony bridging was observed (Fig. 1D). At eight weeks, all six osteoperiosteal gaps were bridged by a newly formed bone. Of these, five had two cortices and a medullary cavity (Figs $1 \mathrm{E}$ and $1 \mathrm{~F}$ ). The coral implant was almost totally resorbed.

Histological findings. In the control group no bony union was observed at four and eight weeks. The defects appeared to have been invaded by fibromuscular tissue. At 16 weeks one-third of the osteoperiosteal gap had repaired.

In the CC-group at four weeks, bone formation and coral resorption were weak and localised mostly in the proximal and distal zones of the implant at the interface between the bone and the implant. Woven bone was observed in direct apposition to coral (Fig. 2A). Cartilage was found only at 

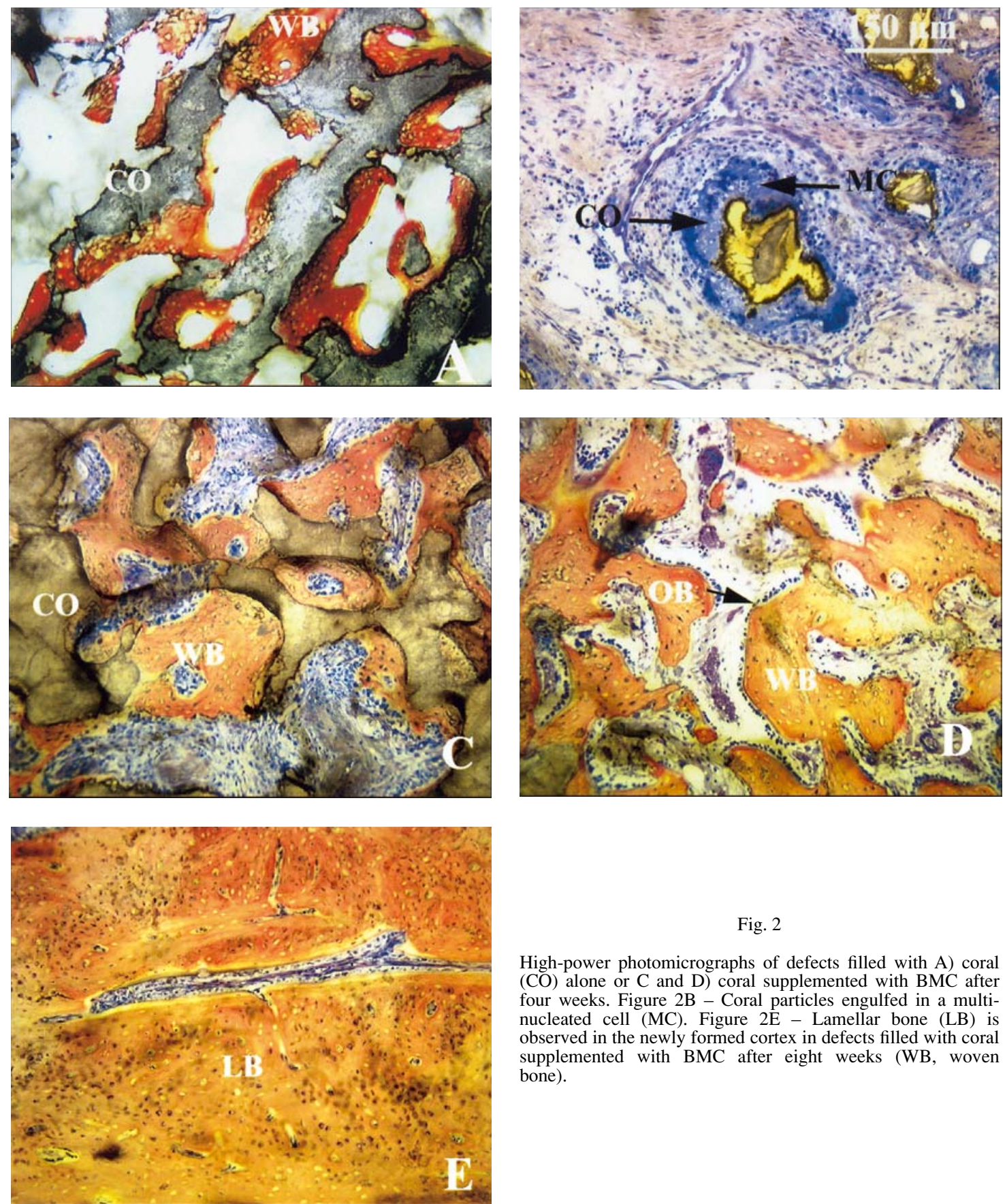

Fig. 2

High-power photomicrographs of defects filled with A) coral (CO) alone or $\mathrm{C}$ and D) coral supplemented with $\mathrm{BMC}$ after four weeks. Figure 2B - Coral particles engulfed in a multinucleated cell (MC). Figure 2E - Lamellar bone (LB) is observed in the newly formed cortex in defects filled with coral supplemented with BMC after eight weeks (WB, woven bone).

the junction between the implant and the adjacent bone. In the central area, most of the porosities were empty or invaded by fibrous tissue. Very little bone was observed in the central area. At eight weeks, bone formation had not increased, but there was an increase in resorption of coral at the interface between the host bone and the implant.

In the CC-BMC group before implantation, bone-marrow smears showed features of a yellow bone marrow with numerous adipocytes and stromal cells, and very few haematopoietic cells. Histological examination of hybrid implants showed that cells were present throughout, but mainly at the periphery. At four weeks, addition of BMC to coral led to a drastic increase in cellular activities compared with $\mathrm{CC}$ alone. These activities were distributed more uniformly throughout the implant than in CC implants. Areas of active osteoblasts were observed along coral surfaces (Figs 2C and 2D) contiguous to multinucleated resorbing cells. Multinucleated cells were observed along the perimeter of coral walls or englobing coral particles (Fig. 2B). In some locations, coral had been replaced by new woven bone with a pattern similar to that of coral architecture (Figs 2C and 2D). Vascularisation was abun- 
dant throughout the implant. As in CC implants, cartilage was found only at the interface between the bone and coral. In one of the specimens, cartilage was found at the site of a fracture of the implant. Osteogenesis seemed to have occurred through an intramembranous process. At two months, bone remodelling was observed. In the most favourable cases a cortex similar to the adjacent diaphysis of the radius was seen (Fig. 2E). Haematopoietic zones and adipocytes were also present in what seemed to be a new medullary cavity. At that stage the coral had been almost completely resorbed.

Histomorphometric findings. At four weeks, BSA was superior in the CC-BMC group in comparison with BSA in the $\mathrm{CC}$ group $(22 \pm 13 \% \vee 2 \pm 2 \% ; \mathrm{p}=0.01)$. At eight weeks, BSA had increased. Osteogenesis in cavities filled with $\mathrm{CC}-\mathrm{BMC}$ was significantly higher than in cavities filled with CC $(30 \pm 13 \% \vee 8 \pm 8 \% ; \mathrm{p}=0.04)$.

At four weeks, the addition of fresh autologous bonemarrow cells to coral led to a significant decrease in the surface area $(59 \pm 17 \% v 33 \pm 6 \%, \mathrm{p}=0.03)$. At eight weeks, no statistical differences in the resorption of coral were observed between the two groups $(34 \pm 17 \%$ v $14 \pm$ $8 \%$ ). Moreover, the residual coral in the defect decreased by almost $50 \%$ between one and two months in both groups (59\% to $34 \%$ for the CC group and $33 \%$ to $14 \%$ for the CC-BMC). This decrease was significant only in the CCBMC group $(\mathrm{p}=0.009)$.

\section{Discussion}

Clinically, coral is used with success in spinal fusion, ${ }^{14,15}$ cranial surgery, ${ }^{16}$ and dentistry. ${ }^{17}$ It is osteoconductive but is not osteogenic.

In our study a $2 \mathrm{~cm}$ osteoperiosteal gap was not repaired spontaneously after two months, but bony bridging occurred in one out of three animals after four months. These data suggest that the model is one of delayed union rather than of nonunion as previously proposed by Tuli and Gupta. ${ }^{18}$

In osteoperiosteal gaps bridged with coral only, the porosities were invaded with fibrous tissue or were empty. Occasionally, bone formation was observed in direct contact with coral confirming its osteoconductivity, but it was insufficient to allow union. These findings are similar to those reported using hydroxyapatite. When the gap reaches a critical size, $20 \mathrm{~mm}$ in dogs, ${ }^{19} 5 \mathrm{~mm}$ in rats ${ }^{20}$ the osteoconductive properties of the material are insufficient to fill the gap with formation of new bone. Therefore this model proved to be adequate for the evaluation of coral as a scaffold for bone-marrow cells.

Ohgushi et $\mathrm{al}^{21}$ and Vuola et $\mathrm{al}^{22}$ demonstrated that supplementation of coral with whole marrow increased osteogenesis in the ectopic model. We have shown that addition of BMC to coral led to an enhancement in osteogenesis in large bone defects in adult rabbits. Bone formation occurred in sufficient amounts to allow union of the defects. Similarly, addition of whole marrow to osteo- conductive material such as tricalcium phosphate, hydroxyapatite and biphasic hydroxyapatite-tricalcium phosphate in dogs, 9,10 and hydroxyapatite-tricalcium phosphate in rats $^{20,23}$ has a positive influence on the formation of bone in the orthotopic model. More unexpected is the formation of cortex and of a medullary canal with mature lamellar bone observed in the most favourable cases. Previous studies in vitro have shown that coral supports the attachment, growth and differentiation of bone-marrow stromal cells. ${ }^{24}$ Our study suggests that coral is a suitable resorbable carrier for bone-marrow cells in vivo. It can serve as a substrate for BMC attachment and growth, and as a template to guide bone morphogenesis in a clinically relevant volume.

As previously stated, autologous grafts must be considered as the treatment of choice. We did not include in our study a group with cortical autologous grafts. It has already been shown that autologous bone grafts could provide healing of such a defect in a similar model. ${ }^{25-27} \mathrm{We}$ decided not to study a group with BMC alone because this cannot be used in clinical cases for such large defects of a long bone. The cell suspension needs a rigid scaffold or a gel to be maintained in the defect to avoid dispersion of the cells and formation of ectopic bone. The use of bonemarrow cells alone ${ }^{8}$ or marrow plugs ${ }^{28}$ should be limited to closed cavities or small defects.

In our study, the kinetics of coral resorption were slow enough to allow it to act as a scaffold for osteoprogenitor cells. Addition of whole marrow increased resorption of coral. This suggests that resorbing cells survived the grafting procedure and are still active. From a clinical point of view, addition of a larger quantity of bone marrow or of a bone marrow contaminated with blood monocytes may induce too rapid resorption of the implant, leading to failure of repair.

A number of growth factors are present in the bone matrix and presumably released during bone resorption. ${ }^{29}$ Further work should explore the possibility of incorporating osteogenic growth factors which could couple osteogenesis and material resorption.

Supplementation of coral with bone-marrow cells increased both material resorption and osteogenesis in defects of clinically relevant volumes. Coral was suitable as a substrate for resorbing cells and seemed to act as a template maintaining cells in the defect and scaffold for bone morphogenesis. This dual influence of whole marrow emphasises that it contains osteoprogenitor as well as cells with the capacity of resorbing materials.

We thank Inoteb (France) for their donations of coral implants (Biocoral), C. De Pollak and K. Oudina for their excellent technical assistance, P. Masquelier for her excellent animal care, and G. Guillemin for helpful discussions.

This work was supported by INSERM, CNRS and Fondation pour la Recherche Médicale.

Although none of the authors have received or will receive benefits for personal or professional use from a commercial party related directly or indirectly to the subject of this article, benefits have been or will be received but are directed solely to a research fund, foundation, educational institution, or other non-profit institution with which one or more of the authors is associated. 


\section{References}

1. Damien CJ, Parsons JR. Bone graft and bone graft substitutes: a review of current technology and applications. I of Applied Biomaterials 1991;2:187-208.

2. Langer R, Vacanti JP. Tissue engineering. Science 1993;260:920-6.

3. Beresford JN. Osteogenic stem cells and the stromal system of bone and marrow. Clin Orthop 1989;240:270-80.

4. Triffitt JT. The stem cell of the osteoblast. In: Bilezikian JP, Raisz LG, Rodan GA, eds. Principles of bone biology. San Diego, etc: Academic Press, 1996:39-50.

5. Caplan AI, Bruder SP. Cell and molecular engineering of bone regeneration. In: Lanza RP, Langer R, Chick L, eds. Principles of tissue engineering. Georgetown, Texas: R. G. Landes and Academic Press, 1997:603-19.

6. Ohgushi H, Goldberg VM, Caplan AI. Heterotopic osteogenesis in porous ceramics induced by marrow cells. J Orthop Res 1989;7: 568-78.

7. Oghushi H, Okumura M, Tamai S, Shors EC, Caplan AI. Marrow cell induced osteogenesis in porous hydroxyapatite and tricalcium phosphate: a comparative histomorphometric study of ectopic bone formation. J Biomed Mater Res 1990;24:1563-70.

8. Werntz JR, Lane JM, Burstein AH, et al. Qualitative and quantitative analysis of orthotopic bone regeneration by marrow. J Orthop Res 1996; $14: 85-93$

9. Johnson KD, Frierson KE, Keller TS, et al. Porous ceramics as bone graft substitutes in long bone defects: a biomechanical, histological, and radiographic analysis. J Orthop Res 1996;14:351-69.

10. Grundel RE, Chapman MW, Yee T, Moore DC. Autogeneic bone marrow and porous biphasic calcium phosphate ceramic for segmental bone defects in the canine ulna. Clin Orthop 1991;266:244-58.

11. Irigaray JL, Oudadesse H, EI Fadl H, et al. Effet de la température sur la structure cristalline d'un Biocorail. J Thermal Analysis 1993;39:3-14.

12. Tuli SM, Singh AD. The osteoinductive property of decalcified bone matrix: an experimental study. J Bone Joint Surg [Br] 1978;60-B: 116-23.

13. Guillemin G, Meunier A, Dallant $P$, et al. Comparison of cora resorption and bone apposition with two natural corals of different porosities. J Biomed Mater Res 1989;23:765-79.

14. Pouliquen JC, Noat M, Verneret C, Guillemin G, Patat JL. Coral as a substitute for bone graft in posterior vertebral arthrodesis in childhood. Rev Chir Orthop 1989;75:360-9.

15. Zajour W, Dehoux E, Deprey F, Segal P. Use of coral as a bone graft substitute for anterior fusion of lower spine. Orthopaedic Product News 1992:38-9.
16. Roux FX, Brasnu D, Loty B, George B, Guillemin G. Madreporic coral: a new bone graft substitute for cranial surgery: a review of twenty cases. J Neurosurg 1988;69:510-3.

17. Yukna RA. Clinical evaluation of coralline calcium carbonate as a bone replacement graft material in human periodontal osseous defects. J Periodontol 1994;65:177-85.

18. Tuli SM, Gupta KB. Bridging of large chronic osteoperiosteal gaps by allogeneic decalcified bone matrix implants in rabbits. J Trauma 1981;21:894-8.

19. Guillemin G. Contribution à l'étude du devenir d'un fragment de squelette de corail madréporaire implanté dans la diaphyse des os longs chez le chien. Université Paris VII, Thesis, 1981.

20. Ohgushi H, Goldberg VM, Caplan AI. Repair of bone defects with marrow cells and porous ceramic: experiments in rats. Acta Orthop Scand 1989;60:334-9.

21. Ohgushi H, Okumura M, Yoshikawa T, et al. Bone formation process in porous calcium carbonate and hydroxyapatite. J Biomed Mater Res 1992;26:885-95.

22. Vuola J, Goransson H, Bohling T, Asko-Seljavaara S. Bone marrow induced osteogenesis in hydroxyapatite and calcium carbonate implants. Biomaterials 1996;17:1761-6.

23. Wolff D, Goldberg VM, Stevenson S. Histomorphometric analysis of the repair of a segmental diaphyseal defect with ceramic and titanium fibermetal implants: effects of bone marrow. J Orthop Res 1994; 12:439-46.

24. Petite H, Kacem K, Triffitt JT. Adhesion, growth and differentiation of human bone marrow stromal cells on non-porous calcium carbonate and plastic substrata: effects of dexamethasone and 1,25 dihydroxyvitamin D3. J Mater Sci Mater in Med 1996;7:665-71.

25. Hopp SG, Dahners LE, Gilbert JA. A study of the mechanical strength of long bone defects treated with various bone autograft substitutes: an experimental investigation in the rabbit. J Orthop Res 1989;7:579-84.

26. Mehra V, Gill SS, Dhillon MS, Bhusnurmath SR, Nagi ON. Comparison of fresh autogenous with formalin-preserved allogeneic bone grafts in rabbits: an experimental study. Int Orthop 1993;17: 330-4.

27. Bolander ME, Balian G. The use of demineralized bone matrix in the repair of segmental defects: augmentation with extracted matrix proteins and a comparison with autologous grafts. J Bone Joint Surg [Am] 1986;68-A:1264-74.

28. Takagi K, Urist MR. The role of bone marrow in bone morphogenetic protein-induced repair of femoral massive diaphyseal defects. Clin Orthop 1982;171:224-31.

29. Mundy GR. Bone remodelling and its disorders. London: Martin Dunitz, 1995 